\section{EMBRYRIDDLE Aeronautical University}

SCHOLARLY COMMONS
International Journal of Aviation, Aeronautics, and Aerospace

\title{
Strategies in Developing an Aviation \& Aerospace Skill Ecosystem for the State of Telangana, India - Case Study of TASK -Telangana Academy for Skill and Knowledge
}

\author{
Kim Chua \\ Embry-Riddle Aeronautical University Asia, chuak1@erau.edu \\ Sujiv Nair \\ Telangana Academy For Skill and Knowledge, India, ceo_task@telangana.gov.in \\ M.P Ganesh Dr. \\ Indian Institute of Technology, Hyderabad, mpganesh@iith.ac.in
}

Follow this and additional works at: https://commons.erau.edu/ijaaa

Part of the Adult and Continuing Education Commons, Aerospace Engineering Commons, Aviation and Space Education Commons, Engineering Education Commons, Other Education Commons, University Extension Commons, and the Vocational Education Commons

\section{Scholarly Commons Citation}

Chua, K., Nair, S., \& Ganesh, M. (2019). Strategies in Developing an Aviation \& Aerospace Skill Ecosystem for the State of Telangana, India - Case Study of TASK -Telangana Academy for Skill and Knowledge. International Journal of Aviation, Aeronautics, and Aerospace, 6(1). https://doi.org/10.15394/ ijaaa.2019.1313

This Position Paper is brought to you for free and open access by the Journals at Scholarly Commons. It has been accepted for inclusion in International Journal of Aviation, Aeronautics, and Aerospace by an authorized administrator of Scholarly Commons. For more information, please contact commons@erau.edu. 


\section{INTRODUCTION}

India is experiencing unprecedented growth in the Aerospace \& Defence (A\&D) industry. Growth in the civil aerospace sector has never been stronger. Initiatives from the government and a refreshingly positive intent on effective governance and execution has lent an air of positivity amongst Indian and global stakeholders alike. India's aerospace $\&$ defence market was over $\$ 10$ billion in 2016 and is predicted to grow at an estimated compound annual growth rate of more 5\% from 2017 to 2024 (Kaushik, 2014). India's talent availability, with engineering colleges producing about 1.5 million engineering graduates annually, is unmatched by any other country around the world (Jewell, Soret, \& Bradley, 2010).

However, the big question continues to remain - Is the talent readily employable?

Realizing the potential of the sector, Telangana government has included the sectors among the thrust areas in its industrial policy. While the state has a younger footprint in aviation and aerospace sector, it has enabled an ecosystem for industries to invest and provide industry-ready manpower with specific skill development initiatives (Global Market Insight, 2017). With the demand for skilled human resources increasing sharply and several challenges in incubating various training initiatives in the aerospace sector, the need was to formulate strategies that address skill development comprehensively across all its segments and at all levels (from high-end skills to entry-level skills). The objective ensures adequate availability of quality human resource across the skill pyramid.

\section{STATE OF TELANGANA}

Telangana, the youngest and 12th largest state of India, was formed in June 2014, with Hyderabad as its capital. The state is land locked by (new) Andhra Pradesh to the south and east, Maharashtra and Karnataka to the west, and Odisha and Chhattisgarh to the north. The capital city of Hyderabad (also the capital for earlier larger Andhra Pradesh state) is a hub for information technology (IT) and pharmaceutical sectors. Telangana also boasts of the country's first Aerospace and Precision Engineering SEZ Park.

\section{Aerospace Park in Telengana}

The State of Telangana boasts of the country's first Aerospace and Precision Engineering Special Economic Zone (SEZ) at Adibatla in the Ranga Reddy district near the capital city of Hyderabad. The major strength of Hyderabad is the presence of about 1,000 aerospace- and defense-related, small and medium enterprises and plans to set up two more similar aerospace parks to accommodate prospective companies in the future. The aerospace SEZ is spread across 350 acres of which only 250 acres has been notified as 
SEZ. Several homegrown and multi-national companies such as Zen Technologies, Tata Advanced Systems Ltd (TASL), Mahindra \& Mahindra, Sikorsky, Pratt \& Whitney, CFM, and Lockheed Martin are already operational at the Aerospace SEZ.

Besides TASL, the state had allotted 30 acres in the SEZ to Nova Integrated Systems, a Tata enterprise, 25 acres to Punj Lloyd, 20 acres to Mishra Dhatu Nigam (Midhani), and 96 acres to Samuha, a consortium of manufacturers including MTAR Technologies Pvt Ltd. Given the locational advantage and existing infrastructure at the SEZ, the Tata Group has decided to base all its aerospace activities in Hyderabad (The Economic Times, 2018). The Company had already committed investments of more than Rs 1,550 crore (approximately 195 million $€$ ) to set up facilities in separate joint ventures with overseas companies such as Sikorsky and Lockheed Martin Aerostructures.

-With Lockheed Martin-TASL, it will make aero structures for the C130 aircraft produced by Lockheed Martin. The partnership with Sikorsky is for producing components for S-92 helicopter cabins. More than 50 cabins have already been produced so far.

-Nova Integrated Systems, will be setting up an integrated aerospace complex to undertake high-end precision electronics manufacturing, assembly, and integration of airborne vehicles.

-B/E Aerospace, one of the leading aircraft cabin and interior products producers, has set up its engineering services division here.

-Pratt \& Whitney, a leader in aircraft manufacturing, has its third global Centre, after the US and China, for training aircraft engineers and technicians near Hyderabad airport.

-CFM International is a 50/50 joint venture between Snecma (Safran Group) and General Electric Company and has opened its fourth CFM56 maintenance training center in Hyderabad to supports its customers throughout India and the region.

\section{Telangana Aviation \& Aerospace Arena}

The central idea is to make Telangana a hub of aerospace and defense where all activities, including R\&D, manufacturing, startups, SMEs, MRO, skilling, and incubation can be positioned in and around a uniquely provisioned aerospace park. The Telangana government has also proposed to set up three more aerospace and defense parks over the next four years with an investment of 2500 crores. After in-depth discussion and analysis, the reasons to create the aviation and aerospace hub are shown in Table 1. 
Table 1

Reasons to Consider Aviation and Aerospace Hub

\begin{tabular}{|l|l|}
\hline HYDERABAD A\&D & Aerospace parks within/close proximity to urban living \\
DRIVERS & centres \\
Unmatched value proposition - superior infrastructure \\
at low cost \\
Abundant availability of skilled manpower \\
Strong defence cluster with established A\&D supply \\
chain \\
Attractive state industrial policy and package of \\
incentives
\end{tabular}




\begin{tabular}{|l|l|}
\hline & $\begin{array}{l}\text { Placements } \\
\text { Industry focused skilling and placement enabled } \\
\text { through Government subsidy. }\end{array}$ \\
\hline $\begin{array}{l}\text { STRONG A\&D } \\
\text { SUPPLY CHAIN } \\
\text { AND VENDOR } \\
\text { BASE }\end{array}$ & $\bullet \begin{array}{l}\text { Hyderabad has > 1000 MSMEs in precision } \\
\text { engineering industry }\end{array}$ \\
& $\bullet \begin{array}{l}\text { Groomed by defence PSUs: Familiar in military } \\
\text { grade manufacturing }\end{array}$ \\
& $\bullet \begin{array}{l}\text { Several SMEs have now grown to be large } \\
\text { suppliers to Global OMEs } \\
\text { Vibrant startup eco system: Ready to provide } \\
\text { innovative solutions }\end{array}$ \\
\hline
\end{tabular}

Aerospace and aeronautical engineering is the third most sought-after profession for engineering students in India. Hyderabad has developed into a major destination for IT/ITES companies and offers comfortable career progression when compared to the core engineering discipline.

However, the existing talent pool is unable to address the growing demand of the aerospace sector. Though the thriving aerospace industry currently attracts talented engineers with a strong engineering background, it is a niche sector in India with high risk factors that also demands skilled workforce. Like any other sector, an ideal candidate must have the right mix of technical knowledge and soft skills. However, the skill gap has become prominent in aerospace manufacturing sector, which needs immediate attention. Bridging the skill gaps to meet the growing demand for talent in the A\&D industry and improving employability is one area in which TASK has made a conscious effort to accelerate and meet growth requirements. It is enabling creation of a skill ecosystem to increase opportunities for sustainability, innovation, and growth.

\footnotetext{
About TASK

The Telangana Academy for Skill and Knowledge (TASK) was established by the Government of Telangana for two main purposes. First, it strives to equip youths with employable skills and secondly to enhance synergies between government, academia, and industry. The value proposition of this organization is to enhance the employability quotient of youths through short-term skilling programs based on industry specific needs. Skill offerings from TASK are designed, delivered and focused on three broad skill areas personal skills, organisational skills, and technology skills. Some of the key initiatives include: forging industry partnerships and skill gap studies. Forging Industry Partnerships

TASK has signed a tripartite MoU with United Technologies Corporation India Private Limited, Embry-Riddle Aeronautical University (ERAU) Asia for collaborating in aviation professional skills, training and research at Hyderabad. One of the key focus areas is to leverage the industry
} 
expertise from Pratt \& Whitney India Training Center located at the Hyderabad International Airport and the academic expertise from EmbryRiddle Aeronautical University in upskilling the faculty and youth.

An action plan has been evolved between the three parties based on a skill gap analysis with specific focus on introducing new short-term industry relevant courses, faculty development programs, and finishing school based on current industry needs. It was imperative that skill training matches international standards and should be able to take care of growth prospects of the trainees to make them job-ready/employable even outside the country. Similar partnerships with GMR Aviation Academy, Cyient, and Bharat Forge have already been initiated.

\section{Skill Gap Study}

A round table session with 23 faculty/HOD's from 9 colleges provided insights on the key focus areas and impact of the gaps as listed below:

\begin{tabular}{|l|l|l|}
\hline & Focus Area & Impact \\
\hline 1 & Industry backing for mini \& major projects & High \\
\hline 2 & Lack of Design Experience & High \\
\hline 3 & $\begin{array}{l}\text { Lack of Experienced Professors, Asst. Professors join } \\
\text { immediately after MTech without exposure to Industry }\end{array}$ & High \\
\hline 4 & Need for Internships for both faculty and students & High \\
\hline 5 & Guest Lectures in the Aerospace Sector & Low \\
\hline 6 & Inability to show parts of missile, plane, helicopters & Med \\
\hline 7 & $\begin{array}{l}\text { Cost of text books for aerospace specialization high and } \\
\text { lack of access to eBooks. }\end{array}$ & Med \\
\hline 8 & Lack of Collaboration with foreign universities & Low \\
\hline 9 & Lack of labs/test facility/simulators & Med \\
\hline 10 & Provision of Adjunct faculty for aeronautical engineering & Low \\
\hline 11 & Soft skills among students & High \\
\hline 12 & Faculty Development Programs on latest technologies & Med \\
\hline 13 & Aerospace Conferences/Professional Associations & Low \\
\hline 14 & $\begin{array}{l}\text { AE taught as a separate major rather than part of Mech } \\
\text { Engineering }\end{array}$ & Low \\
\hline
\end{tabular}

Another study to identify skill gap was commissioned and a private agency was commissioned to understand the gaps especially with focus in the areas of Engineering Solutions \& Maintenance. The survey made use of extensive interactions with a cross section of people from the Industry and students pursuing Aeronautical Engineering \& Aircraft Maintenance Engineering (AME) Courses.

\section{Skill gap among engineering students.}

The observations from the study found that the general willingness of the undergraduates entering the industry has been mostly towards Engineering 
Design/Service. Almost half of the students (48\%) expressed a wish to pursue a career in Engineering Design/Service. Only 4\% wanted to pursue a career in the OEM Sector. Thirteen percent (13\%) wanted to pursue a career in Maintenance \& Repair while the remaining 35\% wanted to pursue higher studies. Some of the key factors leading to this gap:

Lack of curriculum awareness. There is a significant gap between the curriculum and student knowledge. CAD/CAM/CAE, MATLAB, Structural Design, Composite Design, Tool design, and Engineering Methods are important subjects for a student to be informed for entry into the industry. Unfortunately, fewer than $40 \%$ of the final year undergraduates were aware of the importance of these subjects.

Dearth of tool knowledge. More than $50 \%$ of the undergraduate students were not equipped with knowledge on basic tools such as CATIA and MATLAB. While the students had not mastered the tools, the comfort level in utilizing these tools, scored dismally below the benchmark. While the industry expects the students to know about the tools, it does not expect them to master all. It is expected that the student masters at least one tool. The comfort level of the students utilizing a tool was also analyzed. Out of the $46.5 \%$ who were aware of CATIA, $4.1 \%$ were uncomfortable with the tool, $21.8 \%$ are averagely comfortable while only $3 \%$ were adept with the tool. In other words, only 3 out 100 undergraduate students who graduate were comfortable with a tool such as CATIA, similarly with most other tools.

\section{Awareness of Companies}

The students were asked to list out at least 10 companies which operated in the sector including MRO, Engineering Design/Service, OEM's etc. Unfortunately, not more than $70 \%$ of the students could list out even five companies. It was observed that students could list only some of the wellknown in the Industry like Airbus, Boeing, Dassault etc. The majority of them were unable to list out even three companies working in the Engineering Design/Service. This highlights the lack of adequate exposure and knowledge.

\section{Industrial Visits Not Conducted by the Educational Institutions}

Considered to be an integral part of an engineering course, industrial visits offer students an opportunity to interact, enhance knowledge and gain a practical perspective about the industrial environment. The skill gap survey showed that more than $70 \%$ of the final year undergraduate students had never experienced an industrial visit.

\section{Aircraft Maintenance Engineering (AME) Focus}

The AME institutes take in students after their Intermediate $(10+2)$.

During the 3-year AME course, there is very little or no emphasis on nurturing the holistic growth of students. While they are technically advanced as compared to their engineering counterparts, they miss out on the growth due to lack of personal skills. Every training institute and AME student were of the 
same opinion. Most of the AME students rued the lack of proper infrastructural facilities in institutes like the availability of live Jet Engines of heavy aircraft. Lack of knowledge or expertise in various design tools added to their woes. Given their core technical knowledge, additional inputs on design tools will go a long way in ensuring better career prospects.

\section{Maintenance, Repair and Overhaul (MRO) Focus}

Out of 50-60 people who work on an aircraft in the MRO industry, 7 to 10 are engineers and the rest include a majority of technicians. Depending on the size of the operations and complexity (number of aircraft, type of aircrafts, etc.), actual number may vary from one organization to another.

\section{Others}

A few other issues mentioned by the students included infrastructural and exposure to design tools. Students also mentioned lack of an experienced faculty, working models, latest software \& design tools, 3D Printers, Lathe \& $\mathrm{CNC}$ machines and simulators. Students who were aware of some of the tools mentioned above, were of the opinion that the introduction of the tools, in the curriculum as additional courses, would better their career prospects.

\section{The Way Forward}

Based on the skill gap studies and interactions with industry, the following actions plans are being operationalized through TASK to step up the overall skilling for the Aviation and Defense sector in Telangana:

1. Enabling Brainstorming Sessions with Industries to validate skill gaps and evolve programs based on specific industry needs. TASK and Pratt \& Whitney came together to host a round table with aerospace organizations to build a sustainable talent pool to empower the aerospace ecosystem that had interests in the state of Telangana. Some of the key outcomes that came out of this session reinforced that significant job opportunity exists for technicians (structure, design) in addition to engineers. Additional focus areas for future skilling included Aero Specific Program Management (Planning, Tracking \& Looking at Risks), Testing Skills, Power Plant Engineering, Composite Structures, Systems Engineering, Load Estimation, Aerodynamics, High Fidelity Modeling, Aero Data Scientists, Domain Knowledge, Practical, Knowledge/Exposure, Design, MRO focus, Tooling, Aerospace Culture Sensitization - Process, documentation, inspection etc.

2. Conducting Faculty Enablement Programs - Aerospace professionals with rich domain expertise from and CFM and faculty from Cranfield University conduct industry perspective faculty programs for the Aerospace sector. 
3. Identifying Opportunities for Academia through industry interaction, thereby creating awareness on the potential of the aerospace sector.

- Industry Visits for Faculty and Students

- Positioning in Conferences. e.g.: Aviation Conference, CII Sessions etc.

- Inviting Eminent personalities from the Aerospace sector to interact with students

4. Evolving Short-term Courses in Technical Document Writing - Given aviation is a highly-regulated sector with great emphasis on safety, technical manuals or guides play a vital role in this sector. The skill gap study found that there was huge demand for personnel with technical writing/documentation skills. Unlike most other industries, every work involved in MRO sector is meticulously conducted based on manuals and technical documents. Embry-Riddle Aeronautical University and TASK partnered to design and launch a hybrid course in technical writing.

This course provided an introduction to technical writing for aerospace engineering university students. Through both online and face-to-face instruction, students achieved learning outcomes based on rhetorical concepts, basic grammar, and technical writing conventions. Performance-based assessment allowed students to demonstrate their understanding of the constraints and conventions of their future jobs as related to written communication, and their ability to produce such writing within this specific domain. Two pilot programmes have been completed with positive feedback from the students and faculty and the resumes of the certified students have been shared with the potential organizations. Some have already been absorbed into prestigious companies - Capgemini and TASL.

\section{Demand-based Skilling}

Safran Electrical and Power India Pvt Ltd (SEP), an International Aerospace Company and Tier-1 supplier of systems and equipment in the Aerospace and Defense markets operating worldwide, was planning to start its Manufacturing Operations in Telangana. They were looking to hire youths in three job roles that included Electrical Test Operator, Manufacturing Operator, and Quality Inspector.

TASK reached out to Safran to understand the job roles, hiring plan, and specifics for the position and later published these positions via the TASK portal to colleges across Telangana. In four weeks, more than 1000 youths applied for these positions; more than 300 were shortlisted for screening and after multiple rounds of skill tests and interviews, 15 youths were selected to be employed by Safran in their manufacturing plant in Hyderabad. The whole recruitment process was a collaborative effort between TASK and Safran that concluded within 12 weeks. 
Skill ecosystems are communities of interrelated organizations working in a coherent manner to increase opportunities for sustainability, innovation, and growth. The central idea is to make Telangana a hub of aerospace and defense where all activities, including R\&D, manufacturing, MRO, skilling, and incubation can be positioned around a uniquely provisioned aerospace park. With certifications and up-skilling aimed at reaching international standards and training programs being ongoing processes, TASK can soon boast of efforts to take Telangana to higher levels of quality and professionalism in the aviation and aerospace sector. 


\section{References}

Global Market Insight. (2017, September). Industry trends. Retrieved December 11, 2018, from https://www.gminsights.com/industryanalysis/india-aerospace-defense-market

Jewell, J., Soret, C., \& Bradley, P. (2010). CFM presence in India continues to grow. Retrieved from https://www.cfmaeroengines.com/pressarticles/cfm-presence-in-india continues-to-grow/

Kaushik, B. (2014). CII-India skill report2014. Retrieved from https://es.scribd.com/ document/237466987/CII-IndiaSkillReport2014

Telangana Academy for Skill and Knowledge. (n.d.). About us. Retrieved from www.task.telangana.gov.in

The Economic Times. (2018, July 11). Make in India: Telangana to unveil policy for aerospace, defence sectors. Retrieved from https://economictimes.indiatimes.com /news/ defence/make-in-indiatelangana to-unveil-policy-for-aerospace-defence-sectors/ articleshow/51043925.cms 